\title{
Evaluation of variation of instantaneous velocity and reynolds stress due to spherical obstruction in a fluid flow
}

\section{AJIT K. NAYAK}

Received : 09.07.2014; Revised : 06.09.2014; Accepted : 18.09.2014
Author for Correspondence :

\section{AJIT K. NAAK}

Irrigation and Drainage

Engineering Division, Central

Institute of Agricultural

Engineering, BHOPAL (M.P.)

INDIA

Email : anayak62@gmail.com
- ABSTRACT : When a flow passes through a protruding particle, all the turbulent parameters of the fluid subjected to change. So the effect of flow past a protruding particle of spherical shape over a gravel bed was investigated experimentally. All experiments were performed in a $12 \mathrm{~m}$ in length, $0.9 \mathrm{~m}$ in width and $0.71 \mathrm{~m}$ deep horizontal flume. The slope was maintained at 1 in 1400, and depth of water level was $15 \mathrm{~cm}$ with gravel size of $2.6 \mathrm{~mm}$. Three balls of $2 \mathrm{~cm}, 3 \mathrm{~cm}$ and $4 \mathrm{~cm}$ diameter was kept in the test section as the protruding particle. The time-averaged velocity components were measured by the Acoustic Doppler Velocimeter (ADV), Vectrino. The point of interest lies in at $3 \mathrm{~d}$ upstream and $0.5 \mathrm{~d}, 1.0 \mathrm{~d}, 1.5 \mathrm{~d}, 2.5 \mathrm{~d}, 3.5 \mathrm{~d}$, $5.5 \mathrm{~d}, 8.0 \mathrm{~d}$ downstream from the edge of the ball at various depth, where $\mathrm{d}$ is the diameter of the ball. At each section velocity measurements were taken at various vertical intervals. The experimental results have shown that the turbulent flow parameters affect significantly due to protruding particle. The velocity and the Reynolds stress of flow at bottom is negative at immediate downstream of the ball which reduces gradually till $2.5 \mathrm{~d}$ downstream and both are fully recovered after $8 \mathrm{~d}$ downstream of the section.

— KEY WORDS : Turbulence, Flow separation, Time averaged velocity, Reynolds stress

HOW TO CITE THIS PAPER : Nayak, Ajit K. (2014). Evaluation of variation of instantaneous velocity and reynolds stress due to spherical obstruction in a fluid flow. Internat. J. Agric. Engg., 7(2): 432-435. 